\title{
VARIABILITY OF RESPONDING ON A CONCURRENT SCHEDULE AS A FUNCTION OF BODY WEIGHT ${ }^{1}$
}

\author{
Frances K. McSWEeney \\ HARVARD UNIVERSITY
}

\begin{abstract}
Five pigeons pecked for food reinforcers on a concurrent variable-interval one-minute, variable-interval four-minute schedule. Each bird's body weight was varied from $80 \%$ of its free-feeding weight to $95 \%$ and then by $5 \%$ steps to $110 \%$ or until weight gains ceased. The coefficient of variation, but not the standard deviation, of the daily rate of responding on each of the component schedules increased with increases in body weight.
\end{abstract}

The factors that control the variability of conditioned responding have not been studied extensively. Rather, response variability has frequently been attributed to errors of measurement or fluctuations of poorly controlled irrelevant variables. Two theories suggest that response variability represents an important aspect of behavior in its own right, however. First, Skinner's definition of an operant as a class of behaviors (Skinner, 1953) implies that the definition of an operant must take variability into account. Without a knowledge of its variability, the limitations of an operant would be undefined. Second, recent analogies between evolution and behavior (e.g., Staddon and Simmelhag, 1971) suggest that an understanding of variability is important to an understanding of how behavior changes. If new behaviors arise from the action of selective pressure on variants of old behaviors, as these analogies suggest, then behavioral change can only be predicted and controlled if the limitations of and factors controlling these variants are known.

The present study addressed one aspect of the problem of response variability-asking whether the variability of the daily rates of responding emitted on a concurrent variableinterval schedule increases as body weight increases. Conrad, Sidman, and Herrnstein

\footnotetext{
${ }^{1}$ This research was supported by National Science Foundation and National Institute of Mental Health Predoctoral Fellowships to the author. The author wishes to thank Dr. R. J. Herrnstein and Dr. W. M. Baum for their suggestions, and Mrs. A Papp and Mrs. $V$. Upham for their assistance in running the subjects. Reprints may be obtained from the author, Dept. of Psychology, McMaster University, Hamilton, Ontario, Canada.
}

(1958) addressed a similar question. These authors reported that the variability of the interresponse times generated by several fooddeprived rats and one food-deprived monkey increased as satiation proceeded over the course of a single session.

\section{Subjects}

\section{METHOD}

Five adult, male White Carneaux pigeons, each with previous experience with several schedules of food reinforcement, served.

\section{Apparatus}

The subjects worked on a concurrent VI 1-min VI 4-min schedule in a two-key, $30 \mathrm{~cm}$ by $30 \mathrm{~cm}$ by $32 \mathrm{~cm}$ experimental enclosure. The two keys, spaced $9.4 \mathrm{~cm}$ apart, were located $21.25 \mathrm{~cm}$ above the floor. The magazine, placed in the middle of one wall, directly under the point midway between the two keys, was 3 in. $(7.5 \mathrm{~cm})$ above the floor. The magazine and the box itself were illuminated by two white Christmas-tree light bulbs. Two similar white bulbs illuminated the key associated with the VI 1-min schedule; two red bulbs illuminated the VI 4-min key. The keys were operated by a $13.5 \mathrm{~g}(0.135 \mathrm{~N})$ force, and each operation was followed by a brief feedback click.

A changeover delay of $2.5 \mathrm{sec}$ followed all switches from one key to the other. No pecks were reinforced during this time. The keylights were extinguished and pecks were ineffective during reinforcement, which consisted of $3.5 \mathrm{sec}$ of access to the food magazine. The session terminated when 40 reinforcers had been collected. 


\section{Procedure}

Subjects began the experiment at $80 \%$ of their free-feeding body weight. Weights were then raised to $95 \%$, and in $5 \%$ steps thereafter, until they could be raised no higher, or until $110 \%$ of free-feeding weight was reached. Only two birds reached the highest point. One bird could not be raised beyond $95 \%$, and two others, beyond $105 \%$. The 105,95 , and $80 \%$ points were then rerun in order of decreasing body weight to ensure that the order of running was not responsible for the obtained effects on the dependent variable, the coefficient of variation of the rates of responding over the last 10 experimental sessions at each body weight.

At all points, weights were regulated by feeding each bird an amount of food equal to the difference between its scheduled and its actual weights, immediately after each experimental session. Subjects were studied at each weight for at least 30 daily sessions, and then until 10 days of stable responding had been recorded. Responding was considered to be stable when the rate of responding during each of the last 10 sessions fell within the range set by the earlier sessions; i.e., when there was no upward or downward trend.

\section{RESULTS}

Figure 1 presents the mean daily response rate generated by each bird over the last 10 sessions at each body weight. The 105,95 , and $80 \%$ points represent the means of the two points obtained for each weight in the ascending and descending sequences. The sequences have been averaged because the two points for a particular weight never differed by more than $5 \%$. It should be noted that the mean rates of response vary over a large range as body weight is varied.

Figure 2 presents the coefficients of variations of the response rates generated by each bird over the last 10 sessions at each body weight. The coefficient of variation, which is the standard deviation divided by the mean, and multiplied by 100 , provides a measure of variability that has been corrected for changes in the mean level of responding. Again, the 105,95 , and $80 \%$ points represent the average of the points for each body weight obtained in the ascending and descending sequences. It is

apparent that the coefficient of variation for the VI 4-min schedule is consistently greater than that for the VI 1-min schedule, and that the coefficient of variation increases with increases in body weight.

It is possible to argue that changes in the variability of the dependent variable in this study may be artifacts of changes in the variability of the independent variable as its absolute level is varied. In order to test this hypothesis, the coefficients of variation of the birds' daily body weights for the last 10 sessions at each absolute body weight were calculated. The statistics showed no significant trend. Changes in response variability cannot be attributed to changes in the variability of body weight.

\section{DISCUSSION}

Some of the variability of response rate, like the variability of other physical and sen-

BIRD 394
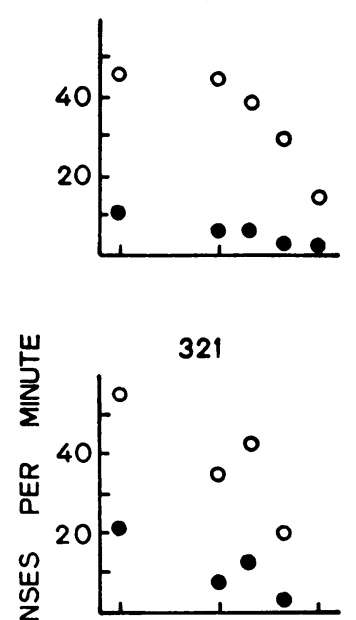

367

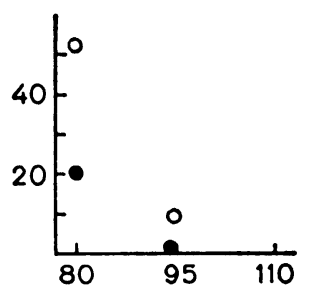

PERCENT WEIGHT

Fig. 1. Mean rate of responding on the VI 1-min and VI 4-min schedules as a function of body weight for each individual bird. 

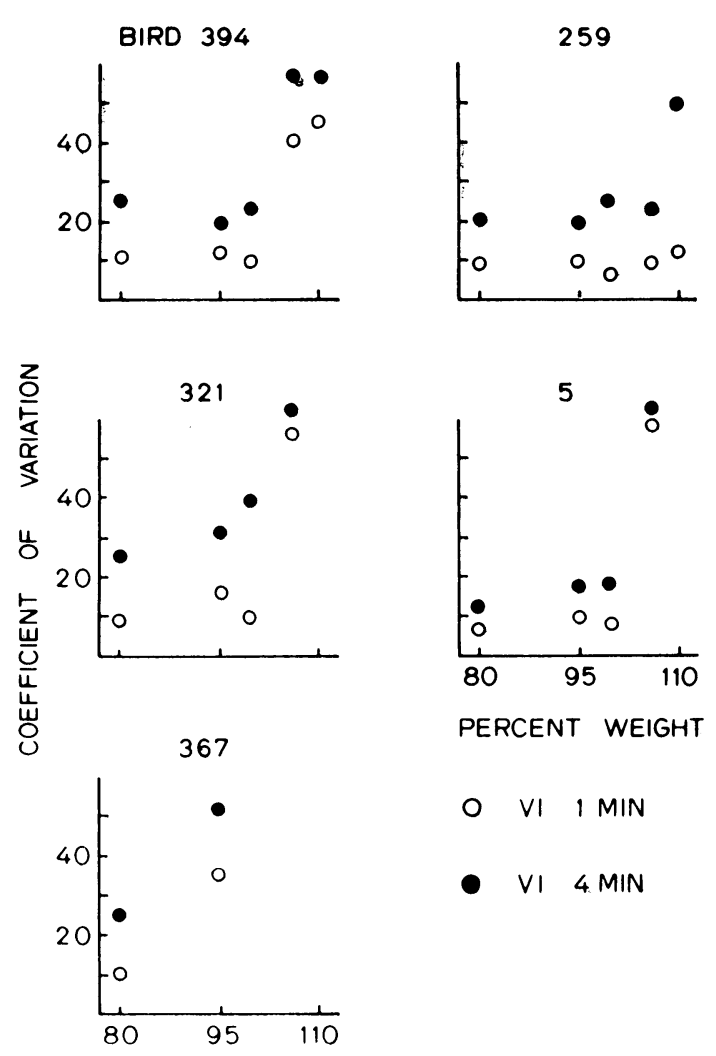

PERCENT WEIGHT

O VI I MIN

- VI 4 MIN

PERCENT WEIGHT

Fig. 2. Coefficients of variation of the rates of responding on the VI 1-min and VI 4-min schedules as a function of body weight for each individual bircl.

sory systems, may be directly proportional to its mean. If this is so, then conventional measures of variability, such as the standard deviation, will only confound these proportional changes with other changes in variability, produced by manipulating the independent variable. The danger that changes in the proportional variability may totally obscure any other trends will be particularly acute when these changes are large. And, the large decreases in the rate of responding with increasing body weight, evident in Figure 1, suggest that the changes will be large in the present case.

Calculation of the coefficient of variation avoids this problem. The increase in the coefficient of variation as body weight increases shows that manipulating body weight does have an effect on variability, which is independent of its effect on mean rate of responding. This effect could not be detected in the disorderly standard deviation data.

Most of the increase in the coefficient of variation occurred above $100 \%$ of free-feeding weight. This was clearly true for Birds 394, 259,321 , and 5 , and the apparent contradiction offered by Bird 367, may be only apparent. The inability to raise this bird's weight above $95 \%$ suggests that its free-feeding weight may have been incorrectly assessed.

The present results are compatible with the results of previous experiments in two ways. First, the decrease in the size of the coefficient of variation with increasing density of reinforcement from a VI 4-min to a VI 1-min schedule, conforms to the earlier findings that denser fixed- (Herrick, 1965) and variable(Herrick and Bomberger, 1965) ratio schedules support less variable behavior than less dense fixed- and variable-ratio schedules. Second, as in many past studies, increasing the density of reinforcement has produced the same effect on behavior as increasing a drive variable. It has been shown here that increasing hunger and increasing the density of reinforcement both lead to less variable rates of responding.

\section{REFERENCES}

Comad, I). G., Sidman, M., and Herrnstein, R. J. The effects of deprivation upon temporally spaced responding. Journal of the Experimental Analysis of Behavior, 1958, 1, 59-65.

Herrick, R. M. Lever displacement under a fixed ratio schedule and subsequent extinction. Journal of Comparative and Physiological Psychology, 1965, 59, 263-270.

Herrick, R. M. and Bromberger, R. A. Lever displacement under a variable ratio schedule and subsequent extinction. Journal of Comparative and Physiological Psychology, 1965, 59, 392-398.

Skinner, B. F. Science and human behavior. New York: The Free Press, 1953.

Staddon, J. E. R. and Simmelhag, V. The "superstition" experiment: a reexamination of its implications for the principles of adaptive behavior. Psychological Review, 1971, 78, 3-43.

Received 29 June 1973.

(Final Acceptance 29 October 1973.) 